Article

\title{
Suppression of Intracellular Reactive Oxygen Species in Human Corneal Epithelial Cells via the Combination of Quercetin Nanoparticles and Epigallocatechin Gallate and In Situ Thermosensitive Gel Formulation for Ocular Drug Delivery
}

\author{
Chuda Chittasupho ${ }^{1,2, *(D)}$, Taepin Junmahasathien ${ }^{1,2}$, , Jiratchaya Chalermmongkol ${ }^{1}$, Raksakul Wongjirasakul ${ }^{1}$, \\ Phuriwat Leesawat ${ }^{1}$ and Siriporn Okonogi ${ }^{1,2}$
}

check for updates

Citation: Chittasupho, C.;

Junmahasathien, T;

Chalermmongkol, J.; Wongjirasakul,

R.; Leesawat, P.; Okonogi, S.

Suppression of Intracellular Reactive

Oxygen Species in Human Corneal

Epithelial Cells via the Combination

of Quercetin Nanoparticles and

Epigallocatechin Gallate and In Situ Thermosensitive Gel Formulation for Ocular Drug Delivery. Pharmaceuticals 2021, 14, 679. https://doi.org/ $10.3390 /$ ph14070679

Academic Editor: Dimitris Tsiourvas

Received: 12 June 2021

Accepted: 12 July 2021

Published: 15 July 2021

Publisher's Note: MDPI stays neutral with regard to jurisdictional claims in published maps and institutional affiliations.

Copyright: (C) 2021 by the authors Licensee MDPI, Basel, Switzerland This article is an open access article distributed under the terms and conditions of the Creative Commons Attribution (CC BY) license (https:// creativecommons.org/licenses/by/ $4.0 /)$
1 Department of Pharmaceutical Sciences, Faculty of Pharmacy, Chiang Mai University, Chiang Mai 50200, Thailand; jiratchaya_newzmine@outlook.com (J.C.); raksakul.sunsun@gmail.com (R.W.); phuriwat.1@cmu.ac.th (P.L.); siriporn.okonogi@cmu.ac.th (S.O.)

2 Research Center of Pharmaceutical Nanotechnology, Faculty of Pharmacy, Chiang Mai University, Chiang Mai 50200, Thailand

* Correspondence: chuda.c@cmu.ac.th (C.C.); taepin.j@cmu.ac.th (T.J.); Tel.: +66-5394-4342 (C.C.); Fax: $+66-5394-4390$ (C.C.)

\begin{abstract}
Oxidative stress can cause several severe ophthalmological diseases. In this study, we developed a thermosensitive gel as a delivery system for two antioxidant substances, namely, quercetin and epigallocatechin gallate. The quercetin was loaded in the PLGA nanoparticles using a solvent displacement method. The physical and chemical stability of the quercetin nanoparticles were evaluated, and the degradation kinetics of the quercetin in the nanoparticles was investigated. The in vitro antioxidant and intracellular reactive oxygen species inhibition of the quercetin nanoparticles, combined with the epigallocatechin gallate (EGCG), were determined using a 2,2-diphenyl-1-picrylhydrazyl radical scavenging assay and a 2,7-dichlorodihydrofluorescein fluorescent probes, respectively. The thermosensitive gel loaded with the quercetin nanoparticles and EGCG was formulated. We confirmed that quercetin nanoparticles displayed the desired physical characteristics, release kinetics, and stability. The combination of quercetin nanoparticles and EGCG suggested the additive effect of antioxidant activity. We also demonstrated the superior intracellular ROS inhibition activity of the quercetin nanoparticles and EGCG with n-acetyl cysteine. The thermosensitive gel showed an appropriate gelation temperature and time for ocular drug delivery. Our results provide promising prospects for applying the thermosensitive gel loaded with quercetin nanoparticles and EGCG as an efficient drug delivery system for antioxidant activity in human corneal epithelial cells.
\end{abstract}

Keywords: ocular drug delivery; oxidative stress; quercetin; epigallocatechin gallate; cornea

\section{Introduction}

Oxidative stress results from an imbalance between reactive oxygen species (ROS) production and the ability of antioxidant ROS scavenging systems. The increased intracellular levels of ROS are associated with cellular and tissue damage, including oxidizing DNA, proteins, and lipid membranes [1]. Oxidative stress can cause several ophthalmological diseases and disorders, including age-related macular degeneration, cataract, uveitis, diabetic retinopathy, glaucoma, and inflammation [2-10]. The eyes' cornea is a barrier against eye injury and trauma caused by the Sun's rays, UV radiation, and pollutants. It is composed of the outer epithelium, corneal fibroblasts, and the inner endothelium. The cornea contains natural antioxidants that remove free radicals and ROS, namely, non-enzymatic antioxidants, such as vitamin $C, \alpha$-tocopherol, and $\beta$-carotene, as well as enzymatic antioxidants, such as superoxide dismutase, catalase, glutathione reductase, and aldehyde 
dehydrogenase [11]. However, the continuous exposure of the cornea to oxidative stress can lead to the accumulation of ROS and oxidative stress generation. Oxidative stress and aging can reduce the level of antioxidants and the activity of antioxidant enzymes, leading to functional and structural changes of corneal epithelial cells, fibroblasts, and endothelial cells [12].

Quercetin is a natural compound that is classified as a polyphenolic flavonoid. Quercetin has shown a strong antioxidant activity by scavenging free radicals, reducing ROS levels, enhancing the expression levels of endogenous antioxidant enzymes, and modulating antioxidant enzyme-related genes, both in vitro and in vivo [13]. Quercetin inhibits oxidative stress and prevents oxidative damage. It was shown to protect cells from genetic toxicity and damage induced by radiation via free radical scavenging and increasing endogenous antioxidant enzyme levels. The limitation of quercetin use is due to its poor water solubility and low bioavailability (5.3\%) [14]. Nanoparticle-based drug delivery systems were exploited to improve the solubility and bioavailability of quercetin. Chen et al. reported that a liposomal copper (II)-quercetin formulation can increase the apparent solubility of quercetin more than 100-fold [15]. Jain et al. presented a quercetin-loaded self-nanoemulsifying drug delivery system (SNEDDS) and showed that quercetin-loaded SNEDDS can enhance antioxidant and anti-cancer efficacy compared with free quercetin [16]. Quercetin Phytosome ${ }^{\circledR}$, a lecithin formulation, significantly improved in vitro solubility and oral absorption in healthy volunteers [17]. Quercetin-loaded polymeric micelles significantly improved the relative oral bioavailability by $286 \%$ compared with free quercetin and extended the half-life of quercetin to 2.19-fold longer [18].

Topical ophthalmic formulations, such as solutions, suspensions, and ointments, are commonly used to deliver the drugs to an anterior segment of the eyes. Topical ocular drug delivery has advantages over other routes of administration due to its non-invasiveness, low systemic side effects, avoiding the first-pass metabolism, and ease of administration [19]. The bioavailability of ophthalmic drugs can be enhanced by prolonging corneal residence time and enhancing drug penetration. Nanoparticles (NPs) have advantages over conventional ophthalmic formulations by extending the drug retention time on the cornea, providing sustained release of the drug, increasing drug permeability and solubility, reducing drug degradation from enzymatic activity, and reducing the frequency of dose [20]. The goal of this study was to develop and analyze the physical and chemical characteristics of the quercetin-loaded PLGA NPs and in situ thermosensitive gel. The in vitro and intracellular antioxidant activity of quercetin-PLGA NPs in combination with EGCG were investigated. The cytotoxicity of the quercetin-loaded PLGA NPs combined with EGCG against human cornea epithelial cells was determined. An in situ thermosensitive gel containing quercetin-loaded PLGA NPs combined with EGCG was developed for an ocular drug delivery system.

\section{Results}

\subsection{Preparation and Characterization of the Quercetin-Loaded PLGA NPS}

The quercetin-loaded PLGA nanoparticles were developed by using the solvent displacement method. Poloxamer $407(0.1 \%)$ and hyaluronic acid (0.05\%, 0.1\%, and 0.2\%) solutions were used as stabilizers based on the biocompatibility with corneal tissue [21,22]. The colloidal characteristics of the quercetin-loaded PLGA NPs coated with poloxamer and HA, including size, polydispersity index, and zeta potential value of the nanoparticles, are shown in Figures 1-3. The quercetin-loaded PLGA NPs that were formulated by using $0.1 \%$ poloxamer 407 as a surfactant had the lowest polydispersity index and the lowest negative charge. The quercetin-loaded PLGA NPs that were developed by utilizing $0.1 \%$ HA as a stabilizer were the smallest, had an acceptable polydispersity index, and had the highest negative surface charge. The negative zeta potential value was due to the free carboxylic groups of hyaluronic acid that coated the quercetin-loaded PLGA NPs. The NPs with a highly negative zeta potential value were expected to be colloidal stable due to the 
repulsive force and hydrophilic steric hindrance between nanoparticles. Therefore, this formulation was selected for further studies.

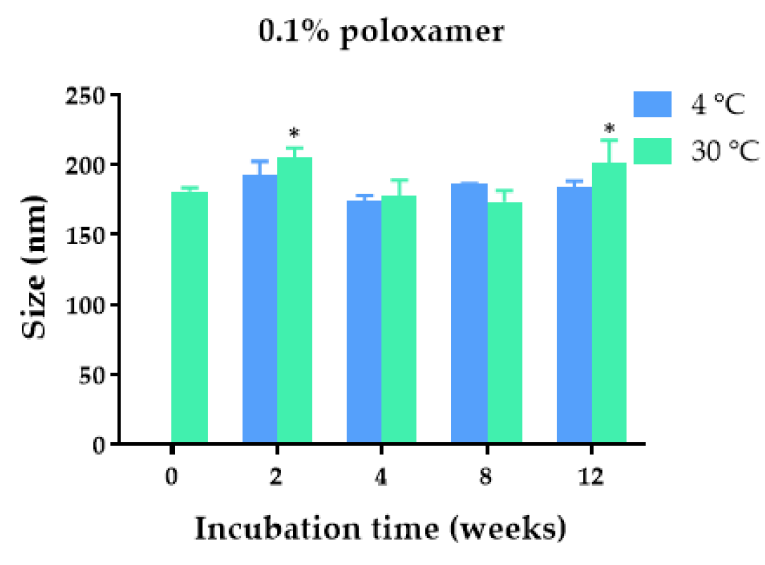

$0.1 \%$ HA

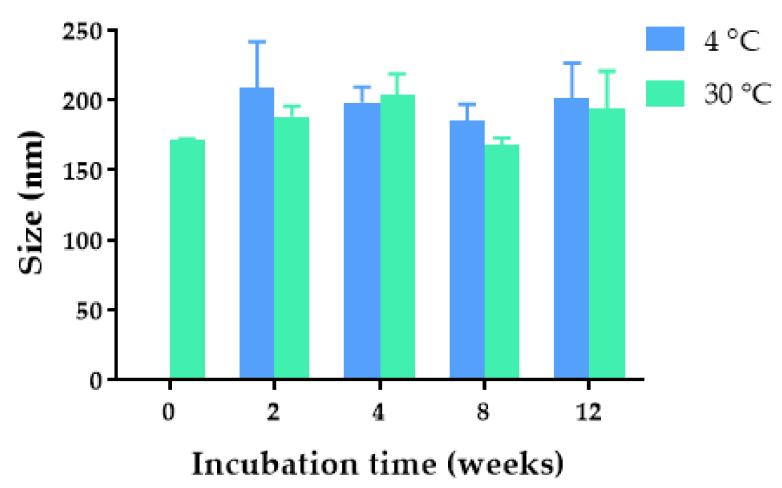

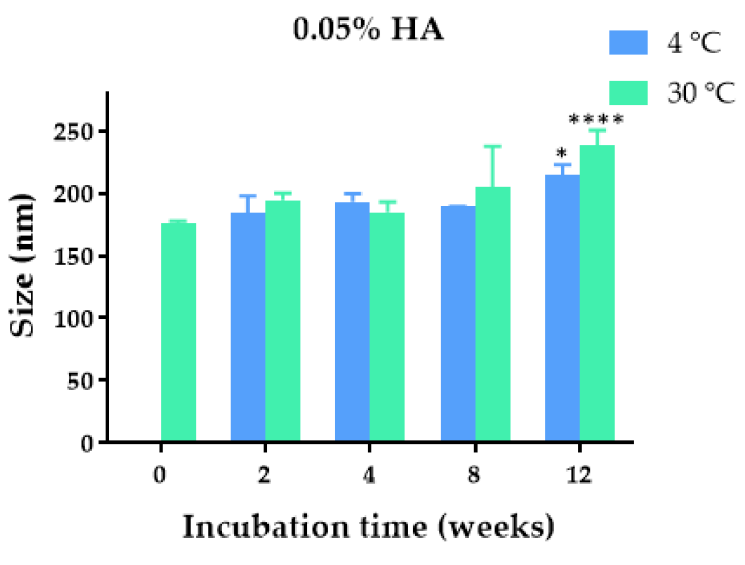

$0.2 \%$ HA

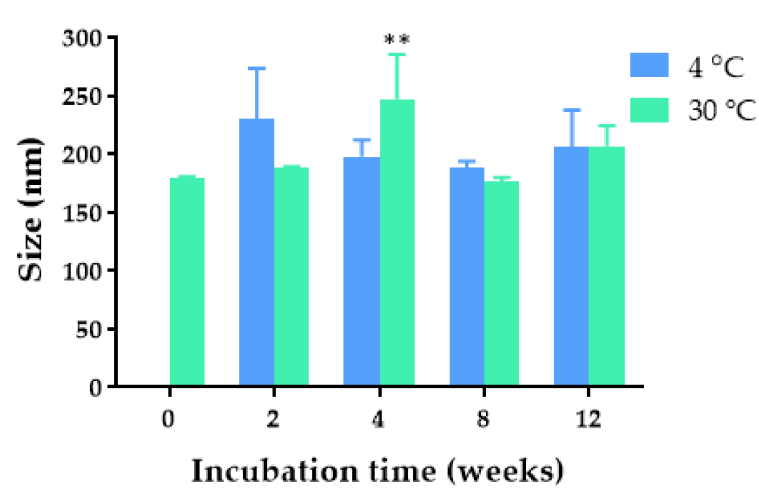

Figure 1. The hydrodynamic diameter of the quercetin-loaded PLGA NPs after fresh preparation and storage in deionized water for $2,4,8$, and 12 weeks at $4^{\circ} \mathrm{C}$ and $30^{\circ} \mathrm{C}$, respectively. ${ }^{*}{ }^{* *}$, and ${ }^{* * *}$ indicate $p<0.05,0.01$, and 0.0001 compared with day 0 , respectively.

\subsection{Physical Stability of the Quercetin-Loaded PLGA NPS in Aqueous Solution}

The physical stability of the quercetin-loaded PLGA NPs in an aqueous solution was examined by measuring the size, polydispersity index, and zeta potential values of the quercetin-loaded PLGA NPs stored at $4{ }^{\circ} \mathrm{C}$ and $30^{\circ} \mathrm{C}$ for 2 weeks and 1, 2, and 3 months. Among all the formulations, the quercetin-loaded PLGA NPs that were stabilized by using $0.1 \%$ HA were mostly stable when stored at $4{ }^{\circ} \mathrm{C}$ and $30^{\circ} \mathrm{C}$. The maximum hydrodynamic diameter was $209 \mathrm{~nm}$ and $204 \mathrm{~nm}$ after storage at $4{ }^{\circ} \mathrm{C}$ and $30^{\circ} \mathrm{C}$, respectively (Figure 1). The sizes of the quercetin-loaded NPs coated with $0.1 \%$ HA stored at $4{ }^{\circ} \mathrm{C}$ and $30^{\circ} \mathrm{C}$ for 3 months were not significantly different compared with that of freshly prepared NPs, suggesting the physical stability of the quercetin-loaded PLGA NPs. The polydispersity indexes of the quercetin-loaded PLGA NPs stabilized with $0.1 \%$ HA ranged from $0.222-0.350$ when they were stored at $4{ }^{\circ} \mathrm{C}$ and $30{ }^{\circ} \mathrm{C}$ for 3 months, indicating a narrow size distribution. It was found that all the quercetin-loaded PLGA NPs coated with different types and concentrations of stabilizers did not have any significant changes in polydispersity index during storage at $4{ }^{\circ} \mathrm{C}$ and $30^{\circ} \mathrm{C}$ for 3 months, suggesting the physical stability of quercetinloaded NPs from surface modification and steric stabilization (Figure 2) [23]. The quercetinloaded PLGA NPs coated with $0.1 \%$ HA had significantly decreased negative zeta potential values when the NPs were stored at $30{ }^{\circ} \mathrm{C}$ for 3 months (Figure 3 ). The zeta potential of the quercetin-loaded NPs did not change after storage at $4{ }^{\circ} \mathrm{C}$ for 3 months. A more negative zeta potential value may result in higher colloidal stability of the nanoparticles due to the electrostatic interaction. The quercetin-loaded PLGA NPs stabilized with $0.1 \%$ poloxamer 
$407,0.05 \% \mathrm{HA}$, and $0.2 \% \mathrm{HA}$ were not as stable as the quercetin-loaded NPs coated with $0.1 \%$ HA. Therefore $0.1 \%$ HA quercetin-loaded PLGA NPs were further investigated for other characteristics.

$0.1 \%$ Poloxamer

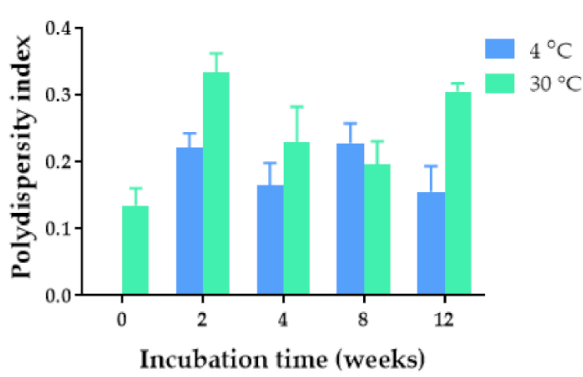

$0.1 \%$ HA

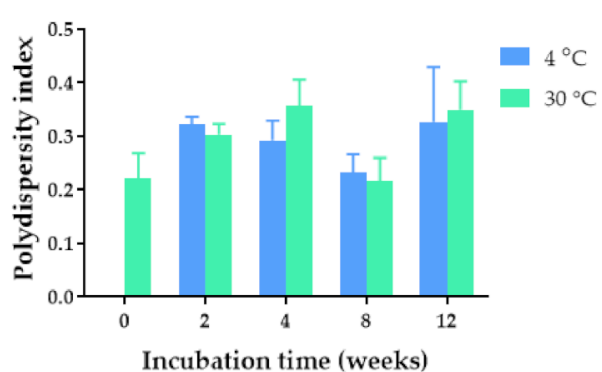

$0.05 \% \mathrm{HA}$

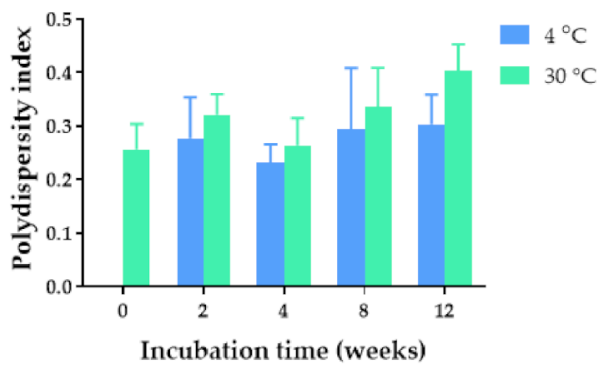

$0.2 \% \mathrm{HA}$

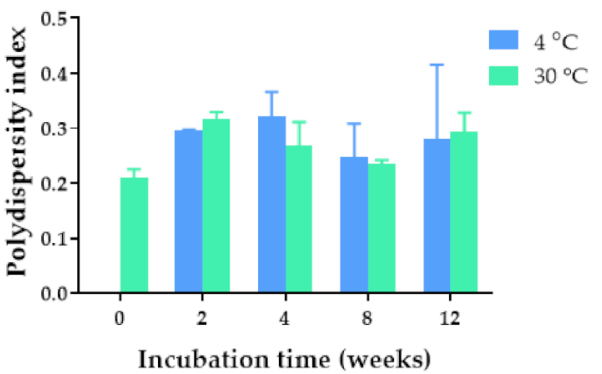

Figure 2. Polydispersity index of the quercetin-loaded PLGA NPs after fresh preparation and storage in deionized water for $2,4,8$, and 12 weeks at $4{ }^{\circ} \mathrm{C}$ and $30{ }^{\circ} \mathrm{C}$.

$0.1 \%$ Poloxamer

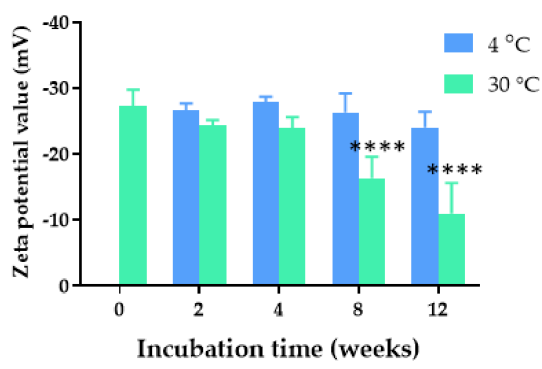

$0.1 \%$ HA

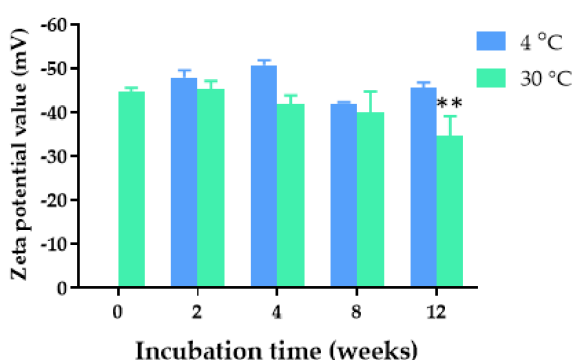

$0.05 \% \mathrm{HA}$

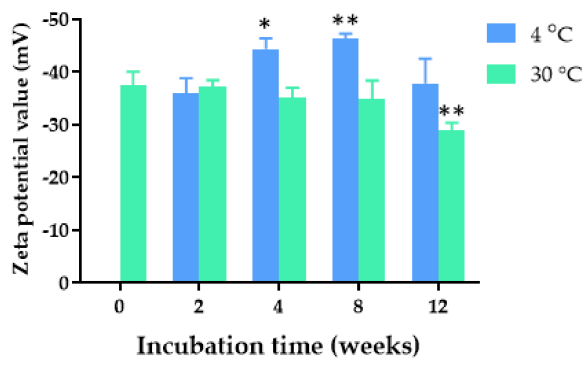

$0.2 \% \mathrm{HA}$

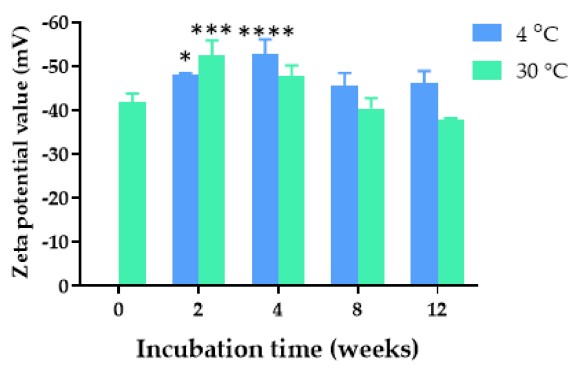

Figure 3. Zeta potential values of the quercetin-loaded PLGA NPs after fresh preparation and storage

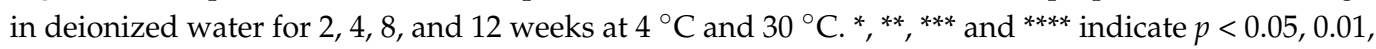
0.001 , and 0.0001 compared with day 0 , respectively.

\subsection{Colloidal Stability of the Quercetin-Loaded PLGA NPs in PBS}

The ability of the quercetin-loaded PLGA NPs to retain their stability in a corneal environment was investigated by evaluating the colloidal stability of the NPs in Dulbecco's phosphate buffer saline, which was used as a simulated tear fluid [24]. The results showed 
no apparent increase in the nanoparticle size, demonstrating colloidal stability of the NPs under the simulated physiological condition (Figure 4). In contrast, the size and size distribution were decreased, which might have been due to the release of quercetin and the electrostatic repulsion with components of the PBS, respectively. The stability of the NPs in PBS could be attributed to the presence of a hyaluronic acid coating on the NPs' surfaces. Hyaluronic acid adsorbed on the surface of PLGA NPs was shown to provide steric hindrance and prevent PLGA NPs from aggregation and precipitation [25].
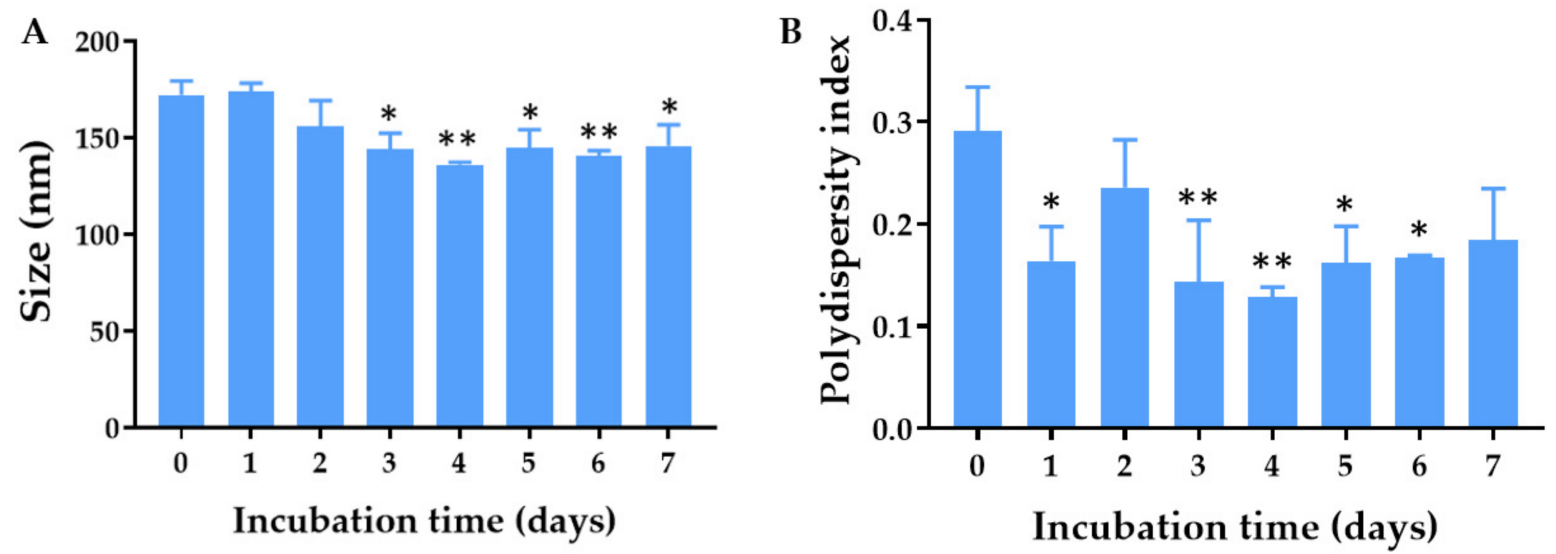

Figure 4. (A) Hydrodynamic diameter and (B) polydispersity index of the quercetin-loaded PLGA NPs after fresh preparation and storage in phosphate buffer saline for $1,2,3,4,5,6$, and 7 days at $37^{\circ} \mathrm{C}$. ${ }^{*}$ and ${ }^{* *}$ indicate $p<0.05$ and 0.01 compared with day 0 , respectively.

\subsection{Encapsulation Efficiency and Release of Quercetin from the Quercetin-Loaded PLGA NPS}

The encapsulation efficiency study showed that $93.83 \pm 6.27 \%$ of the quercetin was entrapped in the $0.1 \%$ HA PLGA NPs. The loading efficiency of quercetin in PLGA nanoparticles was $10.54 \pm 2.34 \%$. The cumulative percent release of quercetin is shown in Figure 5. The burst release of quercetin was observed for the first $12 \mathrm{~h}$ of incubation in PBS at $37^{\circ} \mathrm{C}$, which might have resulted from the release of quercetin adsorbed on the surface of the NPs. After $12 \mathrm{~h}$, the quercetin was released from the PLGA NPs via diffusion of the aqueous medium into the polymer matrix, which was brought about by the diffusion of the encapsulated quercetin toward the bulk aqueous medium [26]. Therefore, the quercetin released from PLGA NPs was matrix-dependent and depended on the erosion rate of the polymer and allowed for the partitioning of quercetin into the aqueous medium. The developed PLGA nanoparticles could improve the solubility of quercetin and sustained the release of quercetin.

\subsection{Chemical Stability of Quercetin in the PLGA NPS}

The percentage remaining of quercetin in the PLGA nanoparticles decreased over the storage time. The degradation rate constant of quercetin $(\mathrm{k})$ was time- and temperaturedependent. There were $40 \%, 35 \%$, and $34 \%$ of the quercetin remaining in the NPs after storage at $4{ }^{\circ} \mathrm{C}, 30{ }^{\circ} \mathrm{C}$, and $45^{\circ} \mathrm{C}$ for 8 weeks, respectively (Figure 6A). The kinetic degradation of quercetin followed a second-order reaction as a plot of 1 / (percentage remaining of quercetin) against time yielded straight lines with the correlation coefficients of 0.9706 , 0.9531, and 0.9718 for kinetic degradation at $4{ }^{\circ} \mathrm{C}, 30^{\circ} \mathrm{C}$, and $45^{\circ} \mathrm{C}$, respectively (Figure $6 \mathrm{~B}$ ). According to the second-order kinetics, the half-lives of quercetin loaded in the NPs were $5.3,4.5$, and 4.1 weeks when stored at 4,30 , and $45^{\circ} \mathrm{C}$, respectively. The Arrhenius plot revealed that the rate constant of the reaction increased with an increasing storage temperature (Figure $6 \mathrm{C}$ ). The results suggested that quercetin-loaded NPs should be stored at $4{ }^{\circ} \mathrm{C}$ to prolong their chemical stability. 


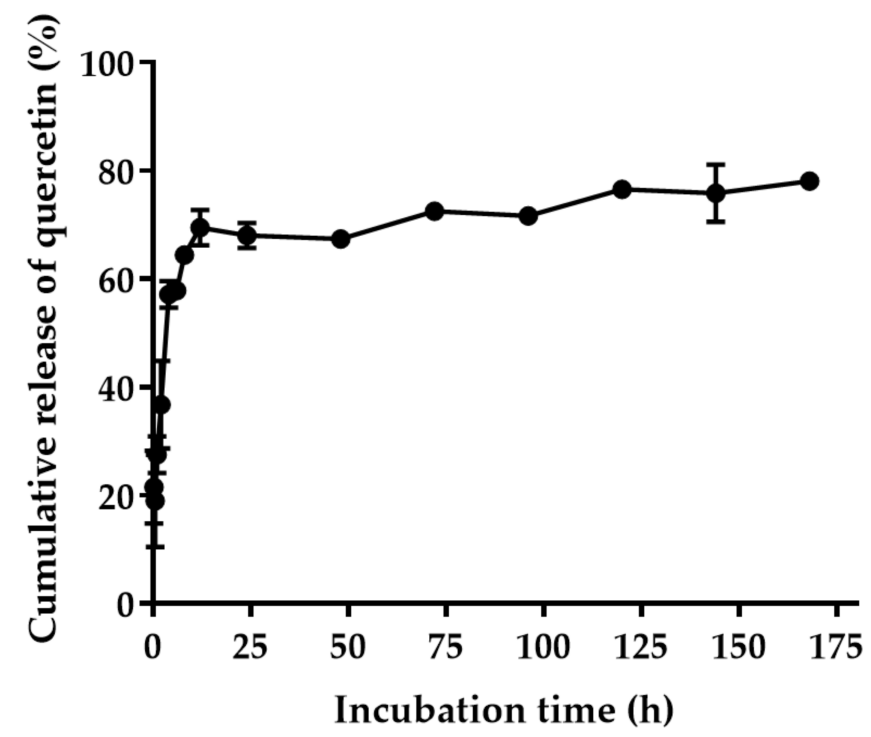

Figure 5. The cumulative release of quercetin from the quercetin-loaded PLGA NPs in phosphate buffer saline, $\mathrm{pH} 7.4$, at $37^{\circ} \mathrm{C}$.
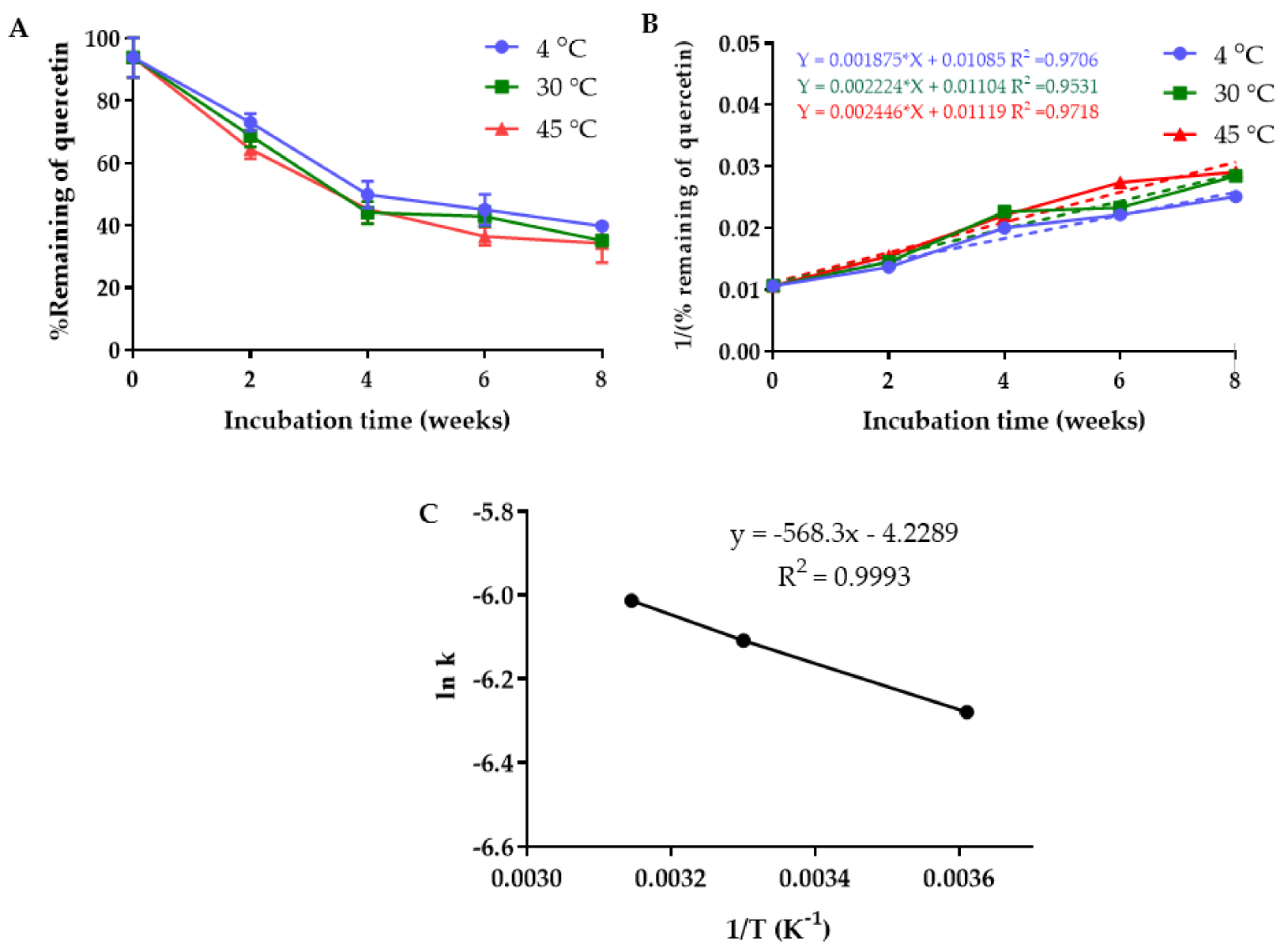

Figure 6. (A) Percentage remaining of the quercetin in PLGA NPs after storage at $4{ }^{\circ} \mathrm{C}, 30{ }^{\circ} \mathrm{C}$, and $45{ }^{\circ} \mathrm{C}$ for 8 weeks. (B) Second-order kinetics model of the quercetin degradation. (C) Arrhenius plot for the quercetin in PLGA NPs degradation. 


\subsection{Antioxidant Activity of Quercetin-Loaded NPs Mixed with EGCG}

The antioxidant activity of the combination of the quercetin-loaded PLGA NPs and EGCG was studied by investigating the free radical scavenging assay. The result was compared with the antioxidant activities of pure quercetin, pure EGCG, the quercetinloaded PLGA NPs, the quercetin-loaded PLGA NPs combined with EGCG, and blank PLGA nanoparticles. The antioxidant activities of all samples, except the blank PLGA NPs, were concentration-dependent (Figure 7). The $\mathrm{IC}_{50}$ values for pure EGCG, pure quercetin, quercetin in PLGA NPs combined with EGCG, and quercetin in PLGA NPs were $4.99 \pm 0.13 \mu \mathrm{g} / \mathrm{mL}, 5.89 \pm 0.25 \mu \mathrm{g} / \mathrm{mL}, 6.71 \pm 0.32 \mu \mathrm{g} / \mathrm{mL}$, and $8.45 \pm 0.23 \mu \mathrm{g} / \mathrm{mL}$, respectively. Blank PLGA NPs did not show any antioxidant effect. The free radical scavenging activity of the quercetin-loaded PLGA NPs combined with EGCG was 1.26-fold higher than that of the quercetin in PLGA NPs alone. These results suggested that the combination of the quercetin-loaded PLGA NPs with EGCG had an additive effect on the antioxidant activity. The lower antioxidant activity of quercetin encapsulated in the PLGA NPs compared with pure quercetin resulted from the slow release of quercetin into the medium.

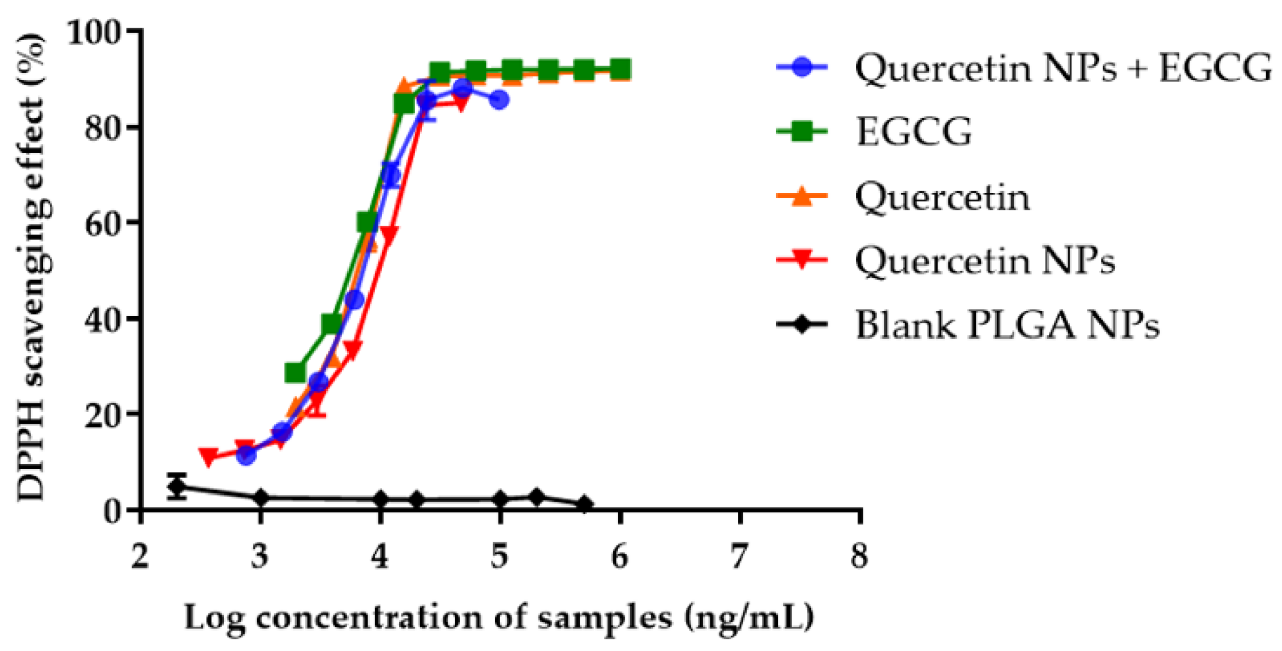

Figure 7. Percentages of the radical scavenging activity of pure quercetin, pure EGCG, quercetinloaded NPs, quercetin- loaded PLGA NPs combined with EGCG, and blank PLGA NPs, which were determined using the DPPH free radical scavenging method.

\subsection{Effects of the Quercetin-Loaded PLGA NPs Combined with EGCG on HCE Cell Viability}

The cytotoxicity of quercetin-loaded in PLGA NPs combined with EGCG was evaluated in the HCE cell line. The cells were exposed to quercetin-loaded NPs combined with EGCG in the concentration range of $0.02-194 \mu \mathrm{g} / \mathrm{mL}$ quercetin and EGCG equivalent. The increase in the concentration of quercetin-loaded PLGA NPs and EGCG decreased the cell metabolic activity of the HCE cell line in a dose-dependent manner (Figure 8). The reduction in the HCE cell metabolic activity suggested an increase in cell death. The $\mathrm{IC}_{50}$ value of quercetin loaded in NPs and EGCG against the HCE cell line was $48.24 \mu \mathrm{M}$. The reduction in cell viability after exposure to a high concentration of quercetin-loaded NPs combined with EGCG was confirmed by observing the HCE cell morphology and cell density. The results showed that some cells that were exposed to quercetin in the NPs and EGCG at concentrations of 25.5-255.1 $\mu \mathrm{M}$ had a spherical shape compared with the spindle shape of normal cells. In addition, there was a decrease in a number of cells after the treatment, with a higher concentration of the quercetin loaded in PLGA NPs and EGCG. These results suggested that at a concentration higher than $5.1 \mu \mathrm{M}$ quercetin-loaded PLGA NPs and EGCG may have cytotoxicity to the HCE cells. Therefore, we selected 2.55, 3.83, and $5.10 \mu \mathrm{M}$ of quercetin in PLGA NPs and EGCG to further investigate the intracellular antioxidant activity. 
A

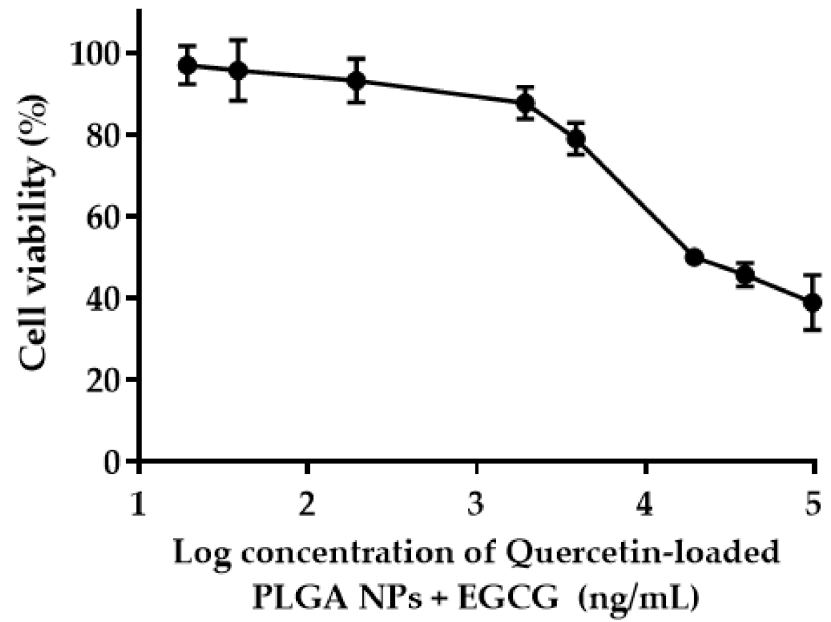

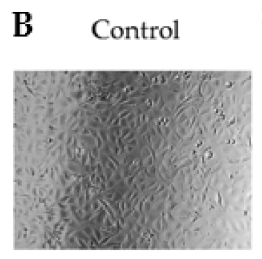

Score $=0$

NPs containing quercetin and EGCG $5.10 \mu \mathrm{M}$

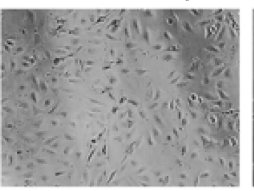

Score $=0$

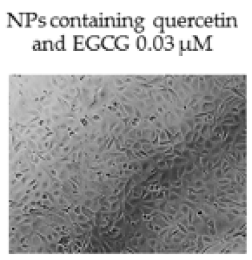

Score $=0$

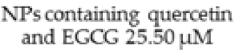
and EGCG $25.50 \mu \mathrm{M}$

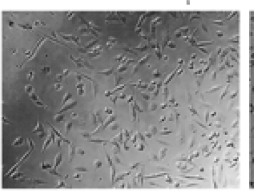

Score $=2$
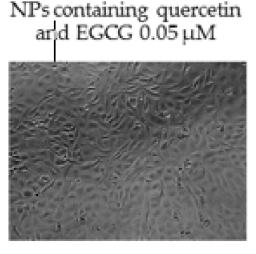

Score $=0$

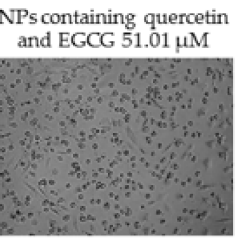

Score $=3$
$\mathrm{NPs}$ containing quercetin
and EGCG $0.26 \mu \mathrm{M}$

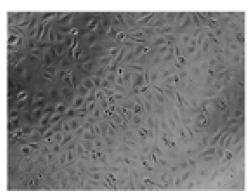

Score $=0$ NPs containing quercetin
and EGCG $127.53 \mu \mathrm{M}$

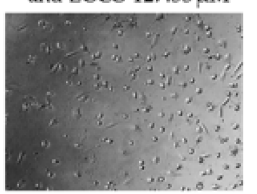

Score $=4$
$\mathrm{NPs}$ containing quercetin
and EGCG $2.55 \mu \mathrm{M}$

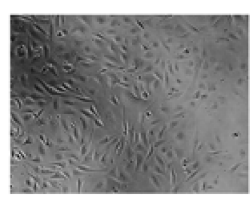

Score $=0$

NPs containing quercetin and EGCG $255.06 \mu \mathrm{M}$

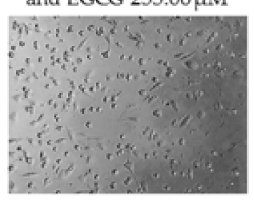

Score $=4$

Figure 8. (A) Effect of quercetin-loaded PLGA NPs combined with EGCG on the HCE cell viability after incubation for $24 \mathrm{~h}$. (B) Changes in the morphology and density of the HCE cells after $24 \mathrm{~h}$ of exposure to various concentrations of quercetin-loaded PLGA NPs and EGCG.

\subsection{Effects of the Quercetin-Loaded PLGA NPs Combined with EGCG on Intracellular ROS Levels}

The cellular ROS generation was induced by applying simulated Sun's rays to the HCE cell line. The results showed that hydrogen peroxide and superoxide anion levels in HCE cells that were exposed to the simulated Sun's rays (negative control) increased significantly compared with those of untreated HCE cells. After the treatment with the positive control ( $5 \mathrm{mM} \mathrm{n}$-acetyl-L-cysteine), the hydrogen peroxide and superoxide anion levels in HCE cells decreased significantly by up to $51.77 \pm 0.64 \%$ and $43.74 \pm 3.07 \%$, respectively (Figure 9). The quercetin-loaded PLGA NPs combined with EGCG containing quercetin and EGCG at 5.1, 3.8, and $2.6 \mu \mathrm{M}$ reduced the hydrogen peroxide levels by up to $22.01 \pm 0.98,37.60 \pm 0.71$, and $57.27 \pm 1.15 \%$, respectively, and reduced the superoxide anion levels by up to $12.76 \pm 2.78,24.71 \pm 3.35$, and $41.28 \pm 1.97 \%$, respectively. The results indicated that quercetin-loaded PLGA NPs combined with EGCG at a lower concentration $(2.6 \mu \mathrm{M})$ had a comparative intracellular ROS inhibition compared with n-acetyl-L-cysteine (5 mM).

\subsection{Gelation Temperature, Gelation Time, and pH of the Quercetin-Loaded PLGA NPs and EGCG} Thermosensitive Gel Loaded In Situ

The $\mathrm{pH}$ values of the in situ thermosensitive gel base at $25{ }^{\circ} \mathrm{C}$ and $33{ }^{\circ} \mathrm{C}$ were $6.85 \pm 0.01$ and $6.76 \pm 0.01$, respectively. After being loaded with the quercetin-loaded PLGA NPs and EGCG, the pH values of the in situ gel at $25^{\circ} \mathrm{C}$ and $33^{\circ} \mathrm{C}$ were $6.69 \pm 0.01$ and $6.70 \pm 0.01$, respectively. These results indicated that the quercetin-loaded PLGA NPs 
and EGCG did not significantly change the $\mathrm{pH}$ of the thermosensitive gel, and the $\mathrm{pH}$ values were suitable for ocular delivery.

A

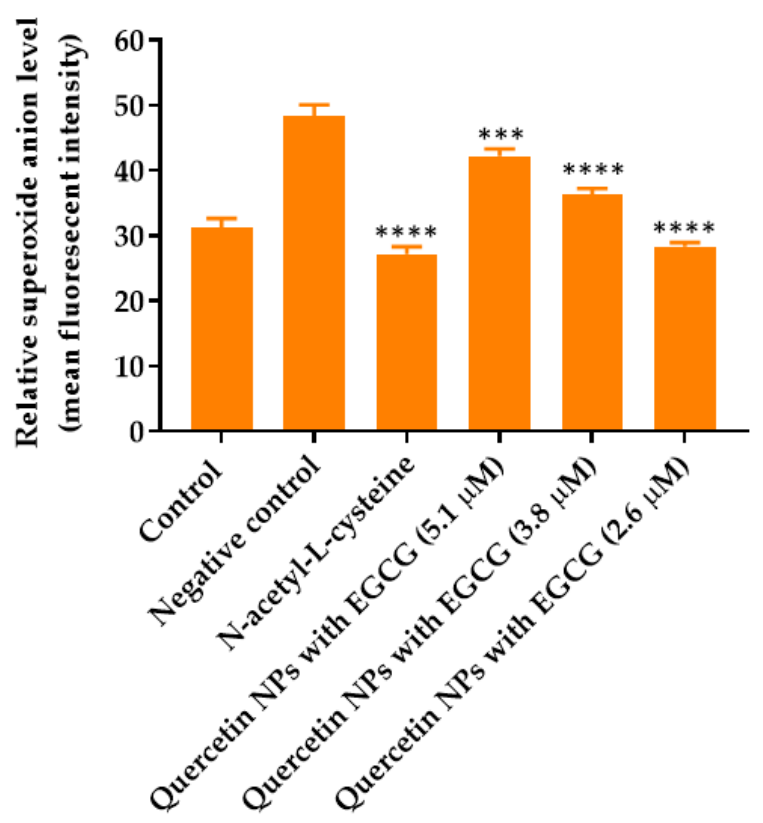

B

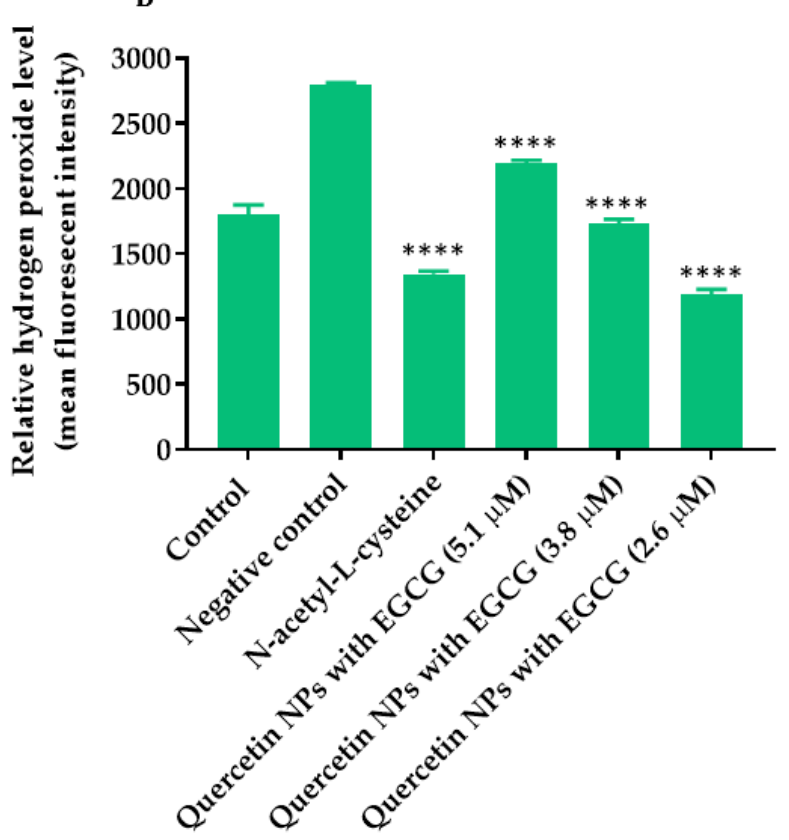

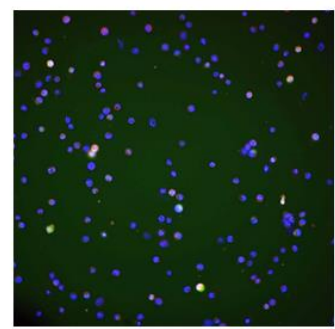

Control

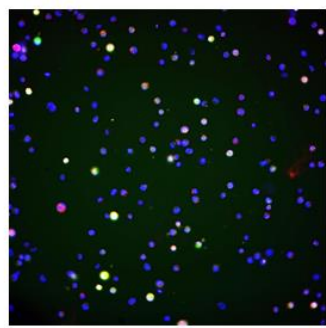

NPs containing quercetin and EGCG at $5.1 \mu \mathrm{M}$

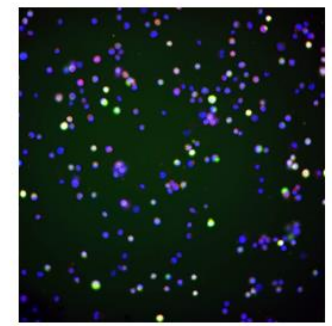

Negative control (Sun's rays) Positive control (NAC)

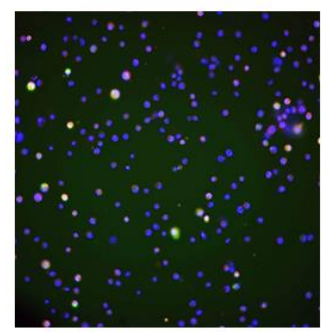

NPs containing quercetin and EGCG at $3.8 \mu \mathrm{M}$

(C)
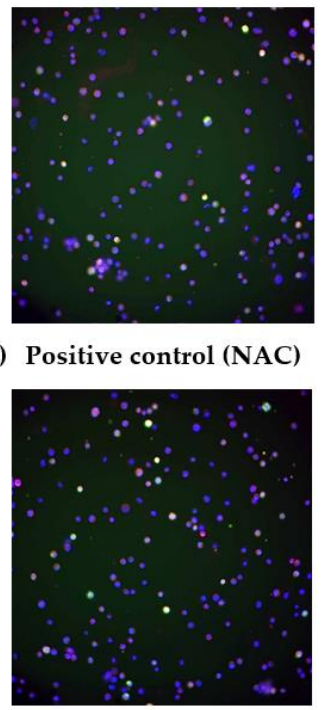

NPs containing quercetin and EGCG at $2.6 \mu \mathrm{M}$

Figure 9. Effect of quercetin loaded PLGA NPs combined with EGCG on intracellular ROS generation. (A) Quantification of the hydrogen peroxide levels within the indicated groups. (B) Quantification of the superoxide anion levels within the indicated groups. (C) Fluorescence microscopy of the HCE cells treated with fluorescent probes after cultivation in the presence and absence of simulated-Sun-ray oxidative stress and the treatment with quercetin loaded PLGA NPs and EGCG. *** and ${ }^{* * * *}$ indicate $p<0.001$ and 0.0001 compared with control, respectively.

Both the in situ thermosensitive gel base and quercetin-loaded PLGA NPs and EGCG thermosensitive gel were liquids at $25^{\circ} \mathrm{C}$. The thermosensitive gel base formed a highstrength gel at $35 \pm 0{ }^{\circ} \mathrm{C}$, while the quercetin-loaded PLGA NPs and EGCG thermosensitive gel demonstrated a gelling temperature of $33 \pm 0{ }^{\circ} \mathrm{C}$ (Table 1). The gelation time for the 
thermosensitive gel base and quercetin-loaded PLGA NPs and EGCG loaded in the gel were 300 and $157 \pm 5.13 \mathrm{~s}$, respectively.

Table 1. Mobility of the in situ thermosensitive gel containing quercetin-loaded PLGA NPs and EGCG upon increasing the temperature.

\begin{tabular}{ccc}
\hline Temperature $\left({ }^{\circ} \mathbf{C}\right)$ & In Situ Gel Base & $\begin{array}{c}\text { In Situ Gel Containing Quercetin-Loaded } \\
\text { PLGA NPs and EGCG }\end{array}$ \\
\hline 28 & $0 \pm 0$ & $1 \pm 0$ \\
29 & $0 \pm 0$ & $1 \pm 0$ \\
30 & $1 \pm 0$ & $1 \pm 0$ \\
31 & $1 \pm 0$ & $1 \pm 0$ \\
33 & $1 \pm 0$ & $2 \pm 0$ \\
34 & $1 \pm 0$ & $2.7 \pm 0.6$ \\
35 & $3 \pm 0$ & $3 \pm 0$ \\
36 & $3 \pm 0$ & $3 \pm 0$ \\
37 & $3 \pm 0$ & $3 \pm 0$ \\
38 & $3 \pm 0$ & $3 \pm 0$ \\
40 & $3 \pm 0$ & $3 \pm 0$ \\
\hline
\end{tabular}

Score: 0 = freely mobilized, $1=$ moderately mobilized, $2=$ slightly mobilized, $3=$ immobilized.

\subsection{Rheology of In Situ Thermosensitive Gel Loaded With Quercetin-Loaded PLGA NPs and EGCG}

The shear stress and shear rate were plotted to evaluate the rheological behavior of the in situ thermosensitive gel loaded with quercetin-loaded PLGA NPs and EGCG. The thermosensitive gel had a decreased viscosity when the shear rate increased (Figure 10). However, it regained the viscosity as the shear rate decreased. These results suggested that the in situ thermosensitive gel loaded with quercetin-loaded PLGA NPs and EGCG had pseudoplastic and thixotropic types of rheology. Under the application of shearing, cross-linking between poloxamer chains was temporarily broken. This resulted in an increase in the fluidity of the gel, or the gel became a sol. When the shear rate decreased, the sol became semisolid (gel) again. The thixotropy property of the in situ gel was shown by the hysteresis loop, which meant that the gel took some time to return to a more viscous state. This phenomenon was observed because polymer chains and nanoparticles required time to reorganize [27].

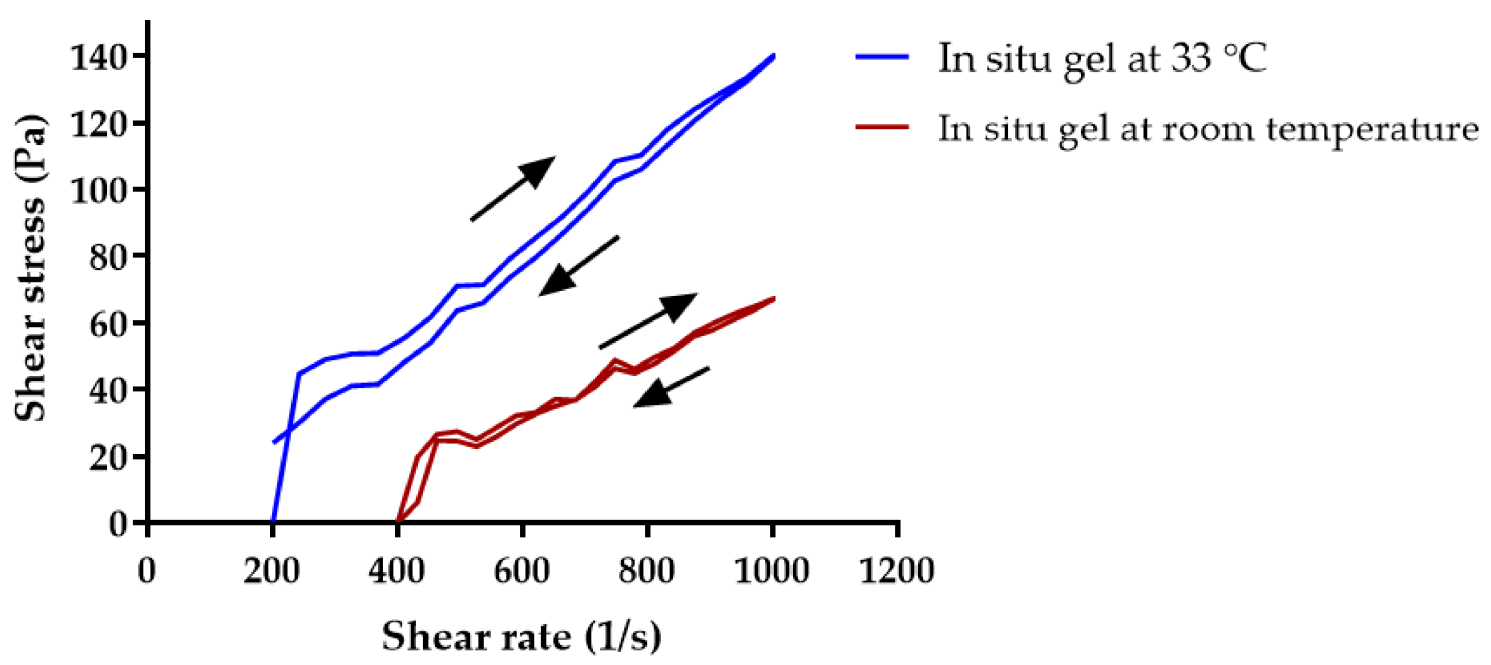

Figure 10. Rheology of the in situ gel loaded with quercetin-loaded PLGA NPs and EGCG at $33^{\circ} \mathrm{C}$ and room temperature. 


\section{Discussion}

The cornea is a tissue that covers the front surface of the eye. Oxidation in the cornea is typically induced by UV radiation and oxidative stress. The human cornea absorbs $92 \%$ of sunlight, radiation, and oxygen [28]. Therefore, the cornea is always exposed to oxidative stress due to ROS, i.e., superoxide, hydroxyl, peroxyl, and hydroperoxyl radical accumulation. Normally, the cornea has a self-developed antioxidant defense mechanism containing non-enzymatic and enzymatic antioxidants. However, with aging, impaired antioxidant defense systems can cause the pathophysiological function of the cornea due to an imbalance between ROS production and clearance. ROS accumulation can result in DNA and cellular damage.

Quercetin is a natural enzymatic antioxidant. The antioxidant activity of quercetin has been extensively studied in recent years. The quercetin glutathione synthesis regulated the enzyme-mediated antioxidant system and regulated signal transduction pathways of reactive oxygen species. A DPPH assay was used to investigate the antioxidant effects of pure quercetin, pure loaded PLGA EGCG, quercetin loaded PLGA NPs, and the combination of quercetin-loaded PLGA NPs and EGCG. The combination of quercetin-loaded PLGA NPs and EGCG significantly enhanced the DPPH free radical scavenging. Interestingly, several reports showed that the combination of quercetin with catechin, epicatechin, or more than two catechin-related compounds resulted in antagonistic antioxidant activity due to their phenolic interaction during oxidation [29,30].

Quercetin was prone to oxidative degradation. Encapsulating quercetin in the PLGA NPs was undertaken to prolong the stability, control the release, and increase the solubility of quercetin. Hyaluronic acid adsorbed on the surface of quercetin-loaded PLGA NPs served multiple functions, including a stabilizer and a mucoadhesive polymer. HA is a glycosaminoglycan possessing a negative charge and high viscosity that could facilitate the adhesion of NPs to the ocular surface. It is one of the compositions of the corneal matrix that is biodegradable, biocompatible, non-irritating, and non-toxic. The mucoadhesive property of HA may increase the retention of quercetin-loaded PLGA NPs to the cornea. In this study, $0.1 \%$ HA significantly enhanced the colloidal stability of the quercetin-loaded PLGA NPs due to electrostatic and steric stabilization. The release of the quercetin from PLGA NPs had two different phases: a quick release of quercetin due to the burst release followed by a sustained release at a constant release rate. The release mechanisms were mainly based on the combination of drug diffusion, polymer swelling, and nanoparticle matrix erosion [31]. Regarding the stability study, quercetin-loaded PLGA NPs were stable in PBS, suggesting that any aggregation of quercetin-loaded PLGA NPs may not be observed upon instillation into the eyes. Quercetin was reported to degrade via photodegradation and oxidation [32]. In an aqueous medium, the quercetin in the PLGA matrix was found to decompose via a second-order reaction in which the reaction may occur between quercetin and oxygen. Wang and Zhao reported that the degradation rate constant of pure quercetin was increased at alkaline $\mathrm{pH}$ and higher temperatures [33].

The reduction in HCE cell viability after exposure to quercetin-loaded PLGA NPs was dose-dependent. The $\mathrm{IC}_{50}$ of quercetin to reduce the viability of breast cancer cells was reported at $50 \mu \mathrm{M}$, which agrees with our finding [34]. DCFH was a fluorescent dye that measured hydrogen and superoxide reactive oxygen species based on the diffusion of the probe into the cells. In the cytoplasm, the dye reacted with esterase enzymes to a non-fluorescent compound called trapped CM-DCFH, which reacted with ROS to form highly fluorescent products. The anti-cellular ROS study revealed the ability of quercetin loaded in PLGA NPs and EGCG at the non-cytotoxic concentrations to reduce the amount of ROS in HCE cells after exposure to the simulated Sun's radiation. The results agreed with a previous study reporting that quercetin decreased UV-B-induced ROS production by HCE cells at $0.5 \mu \mathrm{M}$, although the ROS inhibition of quercetin NPs was never reported. The cellular ROS prevention of quercetin-loaded in PLGA NPs and EGCG decreased when the dose of quercetin loaded in PLGA NPs plus EGCG was increased. This might have been due to the increased cytotoxicity of quercetin-loaded PLGA NPs combined with EGCG. It 
was suggested that $2.6 \mu \mathrm{M}$ of quercetin in NPs and EGCG inhibited ROS production by HCE cells [35].

An in situ thermosensitive gel containing quercetin-loaded PLGA NPs and EGCG was formulated. The in situ thermosensitive gel was designed to be a solution at room temperature to ease instillation and prevent blurred vision. After reaching the cornea, it can be retained at the ocular surface for a longer duration, thus increasing the residence time of quercetin-loaded PLGA NPs and EGCG, which may result in enhanced bioavailability of the active compounds. The sol-to-gel temperature observed in this developed in situ gel formulation was at $33^{\circ} \mathrm{C}$, which was suitable for ocular drug delivery. The literature indicated a normal ocular surface temperature range from $32.9^{\circ} \mathrm{C}$ to $36^{\circ} \mathrm{C}[36,37]$. The viscosity of the gel increased with an increase in temperature. Loading the quercetin-loaded PLGA NPs and EGCG into the in situ thermosensitive gel at a physiological temperature significantly reduced the gelation time to $2.6 \mathrm{~min}$, which was optimal for use.

\section{Materials and Methods}

Materials

Quercetin, epigallocatechin gallate (EGCG), poloxamer 407, and hyaluronic acid sodium salt (HA) with Mws of 8000-15,000 were purchased from Myskinrecipe (Bangkok, Thailand). Poly(DL-lactic-co-glycolic acid) (50:50) with a terminal carboxyl group (PLGA, inherent viscosity $0.22 \mathrm{dL} / \mathrm{g}$, molecular weight of $6700 \mathrm{Da}$ ) was purchased from Lactel Absorbable Polymers (Birmingham, AL, USA). MTT was purchased from Roche Applied Science (Penzberg, Germany). Keratinocyte serum-free medium (SFM), insulin, human recombinant zinc solution, collagen I bovine, human fibronectin, Dulbecco's phosphatebuffered saline (PBS), fetal bovine serum (FBS), penicillin-streptomycin, trypan blue stain $0.4 \%, 0.25 \%$ trypsin-EDTA, and fluorobrite DMEM were purchased from Gibco (Waltham, MA, USA). The HCE cell line, supplements for keratinocyte consisting of epidermal growth factor (EGF), and bovine pituitary extract (BPE) were purchased from ATCC (Manassas, VA, USA)). Hydrocortisone solution and DPPH (2,2-diphenyl-1-picrylhydrazyl) were purchased from Sigma-Aldrich (St. Louis, MO, USA)). ROS/superoxide reagent kit was purchased from Abcam (Waltham, MA, USA).

\section{Methods}

\subsection{Preparation of the Quercetin-Loaded PLGA NPS}

The solvent displacement technique was used to prepare the quercetin-loaded PLGA NPs [38]. The quercetin-loaded PLGA NPs' characteristics were optimized by varying the type and concentration of the stabilizer. PLGA $(62.5 \mathrm{mg})$ and quercetin $(6.25 \mathrm{mg})$ were completely dissolved in $5 \mathrm{~mL}$ of acetone. The solution $(2 \mathrm{~mL})$ was slowly introduced dropwise into $25 \mathrm{~mL}$ of aqueous phase containing $0.05 \%, 0.1 \%$, and $0.2 \% w / v$ hyaluronic acid or $0.1 \%$ poloxamer at a rate of $8 \mathrm{~mL} / \mathrm{h}$ under magnetic stirring (550 rpm). The nanoparticles were continuously stirred for $2 \mathrm{~h}$ to remove residual acetone and were kept in deionized water until characterization. The PLGA nanoparticles without quercetin were prepared for comparative studies.

\subsection{Physical Characterization and Stability of the Quercetin-Loaded PLGA NPS}

The size, size distribution, and surface charges of the quercetin-loaded PLGA NPs were characterized, and the physical stability of the NPs was evaluated. The hydrodynamic diameter, polydispersity index, and zeta potential values of the NPs were determined using a Zetasizer Nano ZS (Malvern Instruments, Worcestershire, UK) based on a dynamic light scattering technique and electrophoretic mobility, respectively [39]. Quercetin-PLGA NPs in deionized water $(1.1 \mathrm{mg} / \mathrm{mL})$ were poured into the light-protected vial and stored at $4{ }^{\circ} \mathrm{C}, 30^{\circ} \mathrm{C}$, and $45^{\circ} \mathrm{C}$ for 12 weeks. At predetermined time intervals- $0,2,4,8$, and 12 weeks - the sizes, PDIs, and zeta potentials of the NPs were determined. 


\subsection{Colloidal Stability of the Quercetin-Loaded PLGA NPs in Dulbecco's PBS}

PBS, pH 7.4, was used as a simulated biological fluid in the eyes as it has the $\mathrm{pH}$ and osmolality of normal tears under normal conditions [40]. The stability of the quercetinloaded PLGA NPs dispersed in PBS was estimated by measuring the size and polydispersity index. The quercetin-loaded PLGA NPs were suspended in PBS, pH 7.4, and stored at $37^{\circ} \mathrm{C}$ for 7 days. At a specific time, samples were taken for measuring the size and polydispersity index.

\subsection{Encapsulation Efficiency and Release of the Quercetin from Quercetin-Loaded PLGA NPS}

The encapsulation efficiency of quercetin in PLGA NPs was determined using a UVvisible spectrophotometry microplate reader (Molecular Devices, San Jose, CA, USA). The quercetin-loaded PLGA NPs $(1.1 \mathrm{mg} / \mathrm{mL})$ were centrifuged at $15,308 \times \mathrm{g}$ for $10 \mathrm{~min}$. Then, the supernatant was removed and the NPs were dissolved in DMSO. The absorbance of quercetin loaded in the NPs was measured at a $\lambda_{\max }$ of $380 \mathrm{~nm}$. The calibration curve was plotted to display the absorbance as a function of quercetin concentration in a range of $1.22-156.25 \mu \mathrm{g} / \mathrm{mL}$, with the $\mathrm{R}^{2}$ value of 0.9996 , without the interference of PLGA and HA absorbance. The encapsulation efficiency and drug loading were calculated using Equations (1) and (2), respectively.

$$
\begin{gathered}
\text { Encapsulation efficiency }(\%)=\frac{\text { Amount of quercetin added }- \text { Amount of quercetin in NPs }}{\text { Amount of quercetin added }} \times 100 \\
\text { Loading efficiency }(\%)=\frac{\text { Amount of quercetin added }- \text { Amount of quercetin in NPs }}{\text { Amount of PLGA }} \times 100
\end{gathered}
$$

The quercetin release profile from quercetin-loaded PLGA NPs was studied by incubating the nanoparticles in the PBS. The quercetin-loaded PLGA NPs was dispersed in PBS, $\mathrm{pH} 7.4$, at a concentration of $0.55 \mathrm{mg} / \mathrm{mL}$ (equivalent to $0.24 \mathrm{mg}$ quercetin) and incubated at $37^{\circ} \mathrm{C}$ for 7 days. At selected time intervals, samples containing quercetin-loaded PLGA NPs were collected and centrifuged at $15,308 \times g$ for $10 \mathrm{~min}$. The nanoparticles were collected and dissolved in DMSO. The amount of quercetin in the NPs was determined by measuring the absorbance at a $\lambda_{\max }$ of $380 \mathrm{~nm}$ using a UV-visible spectrophotometry microplate reader (Spectramax M3, Molecular Devices, San Jose, CA, USA). The amount of quercetin released from the quercetin-loaded PLGA NPs was calculated using a calibration curve. The cumulative release of quercetin (\%) was calculated as per the Equation (3):

$$
=\frac{\begin{array}{c}
\text { Cumulative release of quercetin }(\%) \\
\text { Initial amount of quercetin in NPs-Amount of quercetin remaining in NPs }
\end{array}}{\text { Initial amount of quercetin in NPs }} \times 100
$$

\subsection{Chemical Stability of the Quercetin-Loaded PLGA NPS}

The chemical stability of the quercetin-loaded PLGA NPs was examined in deionized water. The quercetin-loaded PLGA NPs were stored at $4{ }^{\circ} \mathrm{C}, 30{ }^{\circ} \mathrm{C}$, and $45{ }^{\circ} \mathrm{C}$ for 8 weeks. At fixed time intervals, the samples were collected and centrifuged at $15,308 \times g$ for $10 \mathrm{~min}$. The supernatant was discarded and the quercetin-loaded PLGA NPs were dissolved in DMSO. The remaining amount of quercetin loaded in PLGA NPs was quantified using a UV-visible spectrophotometry microplate reader (Spectramax M3, Molecular Devices, San Jose, CA, USA) at a $\lambda_{\max }$ of $380 \mathrm{~nm}$. The data regarding quercetin degradation were fitted with different kinetic equations, including zero-, first-, and second-order kinetics. The best-fitting model was identified using a statistical analysis. It was noted that the selection of the kinetic model was based on the goodness of fit and not based on the mechanism of the degradation of the complex system.

\subsection{Antioxidant Activity of the Quercetin-Loaded PLGA NPs Mixed with EGCG}

The in vitro antioxidant activity of the quercetin-loaded PLGA NPs was determined by using a DPPH free radical scavenging assay. Pure quercetin $(1.95-1000 \mu \mathrm{g} / \mathrm{mL})$, pure EGCG $(1.95-1000 \mu \mathrm{g} / \mathrm{mL}$ ), quercetin-loaded PLGA NPs and EGCG (equivalent to 0.18-94 $\mu \mathrm{g} / \mathrm{mL}$ 
of quercetin and $0.2-100 \mu \mathrm{g} / \mathrm{mL}$ of EGCG), quercetin-loaded PLGA NPs (equivalent to $0.18-94 \mu \mathrm{g} / \mathrm{mL})$, and blank PLGA NPs $(0.2-1000 \mu \mathrm{g} / \mathrm{mL})$ were dissolved or suspended in deionized water. All samples $(100 \mu \mathrm{L})$ were mixed with $500 \mu \mathrm{M}$ DPPH $(100 \mu \mathrm{L})$ in absolute ethanol in 96-well plates. The mixtures were incubated in the dark at room temperature for $30 \mathrm{~min}$. The absorbance was determined at $517 \mathrm{~nm}$ using a UV-visible microplate reader (Spectramax M3, Molecular Devices, San Jose, CA, USA). Absolute ethanol was used as a negative control. The percentage of radical scavenging activity was calculated using Equation (4):

$$
\text { DPPH radical scavenging }(\%)=\frac{[\text { A517control }- \text { A517samples }]}{\text { A517control }} \times 100
$$

The sample concentration that decreased the DPPH free radicals to $50 \%$ of the initial concentration $\left(\mathrm{IC}_{50}\right)$ was calculated using GraphPad Prism 7.

\subsection{Cell Culture}

The cell culture flask was coated with collagen I, bovine fibronectin, and bovine serum albumin for $20 \mathrm{~min}$. A human corneal epithelial (HCE) cell line was cultured in keratinocyte serum-free medium (SFM) supplemented with $1 \%$ penicillin-streptomycin, $5 \mathrm{ng} / \mathrm{mL}$ epidermal growth factor (EGF), $0.05 \mathrm{mg} / \mathrm{mL}$ bovine pituitary extract (BPE), $500 \mathrm{ng} / \mathrm{mL}$ hydrocortisone, and $0.005 \mathrm{mg} / \mathrm{mL}$ insulin and maintained at $37^{\circ} \mathrm{C}$ in a humidified incubator containing an atmosphere of $5 \% \mathrm{CO}_{2}$.

\subsection{Effects of the Quercetin-Loaded PLGA NPs on HCE Cell Viability}

Quercetin $(0.094,0.02,0.094,0.94,1.88,9.4,18.8,47,94 \mu \mathrm{g} / \mathrm{mL})$ in PLGA NPs and EGCG $(0.01,0.02,0.1,1,2,10,20,50,100 \mu \mathrm{g} / \mathrm{mL})$ were diluted in the cell culture medium. HCE cells $\left(3 \times 10^{4}\right.$ cells/well) were plated in 96-well plates and incubated for $72 \mathrm{~h}$ prior to the test. The medium was then removed and cells were rinsed one time with PBS. Then, the quercetin-loaded PLGA NPs combined with EGCG $(200 \mu \mathrm{L})$ at various concentrations were added to the cells and incubated at $37{ }^{\circ} \mathrm{C}$ in $5 \% \mathrm{CO}_{2}$ for $24 \mathrm{~h}$. After incubation, the quercetin-loaded PLGA NPs and EGCG were removed and the cells were washed with PBS. MTT $(1 \mathrm{mg} / \mathrm{mL})$ was added to the cells $(100 \mu \mathrm{L} /$ well $)$ and incubated with the cells for $4 \mathrm{~h}$ at $37^{\circ} \mathrm{C}$ in $5 \% \mathrm{CO}_{2}$. The MTT solution was removed and $100 \mu \mathrm{L}$ of isopropanol was added to solubilize the water-insoluble formazan product. The absorbance was measured at $570 \mathrm{~nm}$. The absorbance values were related to the number of viable cells. The cell viability percentage was calculated using Equation (5), where the control was the viability of untreated cells. The $\mathrm{IC}_{50}$ was calculated based on the non-linear regression analysis.

$$
\text { Cell viability }(\%)=\frac{\mathrm{A} 570 \text { of tested cells }}{\mathrm{A} 570 \text { of control }} \times 100
$$

The change in cellular morphology of the HCE cells was observed under an inverted microscope (EVOS, Thermo Fisher Scientific, Waltham, MA, USA). The score reactivity against the change of cellular morphology was given by the following criteria. Scores of $0,1,2,3$, and 4 indicated none, slightly toxic, mildly toxic, moderately toxic, and severely toxic reactivity, respectively.

\subsection{Effects of the Quercetin-Loaded PLGA NPs Combined With EGCG on Intracellular ROS Levels}

The quercetin-loaded PLGA NPs combined with EGCG at non-toxic concentrations were diluted in a keratinocyte serum-free medium. The HCE cells $\left(1 \times 10^{5}\right.$ cells $\left./ \mathrm{mL}\right)$ were plated in 24-well plates for $24 \mathrm{~h}$ at $37^{\circ} \mathrm{C}$ in $5 \% \mathrm{CO}_{2}$. The NPs and $5 \mathrm{mM} \mathrm{N}$-acetylL-cysteine (ROS inhibitor, a positive control) were incubated with the cells for $30 \mathrm{~min}$ at $37^{\circ} \mathrm{C}$. After incubation, the samples were removed and the cells were washed with PBS ( $500 \mu \mathrm{L} /$ well). Then, PBS (500 $\mu \mathrm{L} /$ well) was added to the cells before exposure to radiation that mimicked the Sun's rays at a dose of $0.32 \mathrm{~J} / \mathrm{cm}^{2}$ (OSRAM UV-lamp, Ultra-vitalux, 
Garching, Germany). The medium was removed and $0.25 \%$ trypsin-versene (300 $\mu \mathrm{L})$ was added and incubated for $2 \mathrm{~min}$ to detach the cells. The cells were washed three times via centrifugation at $1200 \mathrm{rpm}$ for $5 \mathrm{~min}$ at $4{ }^{\circ} \mathrm{C}$. The green fluorescent dye $(\mathrm{Ex} / \mathrm{Em}$ $490 / 525 \mathrm{~nm} ; 1: 2000)$, orange dye (Ex/Em 550/620 nm; 1:1000), and Hoechst 33,342 (5 $\mu \mathrm{M})$ were incubated with the cells at $37^{\circ} \mathrm{C}$ for $45 \mathrm{~min}$. The cells were washed via centrifugation at $400 \times g$ for $5 \mathrm{~min}$ at room temperature. Then, fluorobrite DMEM was added to the cells. The cells were transferred to a 96-well plate to measure the fluorescent intensity by a fluorescence microplate reader (Tecan, Männedorf, Switzerland). The micrographs of cells were taken by fluorescence microscope (INCell analyzer, GE Health Care, Boston, MA, USA).

\subsection{Preparation of Thermosensitive Gel Containing the Quercetin-Loaded PLGA NPS Combined with EGCG}

The thermosensitive gel was prepared by dissolving $16 \mathrm{~g}$ of poloxamer 407 in $100 \mathrm{~mL}$ deionized water. The calculated amount of the quercetin-loaded PLGA NPs, and EGCG (equivalent to $0.94 \mu \mathrm{g} / \mathrm{mL}$ of quercetin and $1 \mu \mathrm{g} / \mathrm{mL}$ EGCG) were added to the poloxamer 407 solution under stirring $(500 \mathrm{rpm})$. The mixture was stored at $4{ }^{\circ} \mathrm{C}$ until characterization.

\subsection{Characterization of Thermosensitive Gel Containing the Quercetin-Loaded PLGA NPS Combined with EGCG}

\subsubsection{Determination of Gelation Temperature}

The mixture of poloxamer 407 and the quercetin-loaded PLGA NPs plus EGCG $(3 \mathrm{~mL})$ was poured in the glass tube and placed in a water bath. The initial temperature of water in the water bath was $28^{\circ} \mathrm{C}$ and elevated in stepwise increments of $1^{\circ} \mathrm{C}$, which was measured by using a thermometer. The gelation temperature was assessed by tilting the tube $90^{\circ}$ until the gel was immobilized. The sol-to-gel transition temperature was the lowest temperature when the gel was unable to mobilize.

\subsubsection{Determination of Gelation Time}

The gelation time of thermosensitive gel containing the quercetin-loaded PLGA NPs and EGCG was assessed by filling the gel $(3 \mathrm{~mL})$ in the tube. The tube was immersed in the water bath where the water temperature was controlled at $33 \pm 0.5^{\circ} \mathrm{C}$, which was a gelation temperature. The sol-to-gel transition time was determined by inverting the tube horizontally every minute. The time at which the gel was unable to mobilize was recorded as the gelation time.

5.11.3. Rheological Measurement of Thermosensitive Gel Containing the Quercetin-Loaded PLGA NPs and EGCG

Measurement of the thermosensitive gel containing the quercetin-loaded PLGA NPs and EGCG rheology was performed using a rheometer (Brookfield) equipped with a plate and plate geometry. The ranging shear rate was from 200 to $1000 \mathrm{~s}^{-1}$ and 400 to $1000 \mathrm{~s}^{-1}$ for the thermosensitive gel at $33^{\circ} \mathrm{C}$ and at room temperature, respectively. The thermosensitive gel was placed in a water bath to maintain the temperature at the gelation temperature.

5.11.4. $\mathrm{pH}$ Measurement of the Thermosensitive Gel Loading Quercetin-Loaded PLGA NPs and EGCG

The $\mathrm{pH}$ of the thermosensitive gel containing the quercetin-loaded PLGA NPs and EGCG was measured in triplicates at $25^{\circ} \mathrm{C}$ using a pH meter (Thermo Fisher Scientific, Waltham, MA, USA).

\subsection{Statistical Analysis}

Statistical analysis of data was completed using an analysis of variance (one-way ANOVA), followed by Newman-Keuls method as a post-hoc test to evaluate the significance of differences (GraphPad Prism 7.02, La Jolla, CA, USA). In all cases, a value of $p<0.05$ was considered statistically significant. All data represent mean $\pm \mathrm{SD}, n=3$ experiments. 


\section{Conclusions}

Quercetin-loaded PLGA NPs were successfully developed and suitable for delivery of quercetin to human corneal epithelial cells. The encapsulation of quercetin into the NPs improved the quercetin solubility, controlled release, physical stability, and chemical stability. The combination of quercetin-loaded PLGA NPs and EGCG increased the antioxidant and intracellular ROS inhibition effects in HCE cells. Thus, quercetin-loaded PLGA NPs combined with EGCG may provide a new approach for delivering quercetin to reduce the reactive oxygen species in the eyes.

Author Contributions: Conceptualization, C.C. and T.J.; investigation, J.C. and R.W.; facility and resources, S.O. and P.L.; writing and editing, C.C.; project administration, C.C. and T.J.; funding acquisition, C.C. All authors have read and agreed to the published version of the manuscript.

Funding: This research was funded by Chiang Mai University Junior Research Fellowship Program, grant number JRCMU2564_014. The APC was funded by Chiang Mai University.

Institutional Review Board Statement: Not applicable.

Informed Consent Statement: Not applicable.

Data Availability Statement: Data is contained within the article.

Conflicts of Interest: The authors declare no conflict of interest.

\section{References}

1. Schieber, M.; Chandel, N.S. ROS function in redox signaling and oxidative stress. Curr. Biol. 2014, 24, R453-R462. [CrossRef] [PubMed]

2. Cejka, C.; Cejkova, J. Oxidative Stress to the Cornea, Changes in Corneal Optical Properties, and Advances in Treatment of Corneal Oxidative Injuries. Oxidative Med. Cell. Longev. 2015, 2015, 591530. [CrossRef]

3. Nita, M.; Grzybowski, A. The Role of the Reactive Oxygen Species and Oxidative Stress in the Pathomechanism of the Age-Related Ocular Diseases and Other Pathologies of the Anterior and Posterior Eye Segments in Adults. Oxidative Med. Cell. Longev. 2016, 2016, 3164734. [CrossRef]

4. Vinson, J.A. Oxidative stress in cataracts. Pathophysiology 2006, 13, 151-162. [CrossRef] [PubMed]

5. Wu, G.S.; Rao, N.A. Photoreceptor mitochondrial oxidative stress in uveitis. Expert Rev. Ophthalmol. 2008, 3, 299-310. [CrossRef]

6. Calderon, G.D.; Juarez, O.H.; Hernandez, G.E.; Punzo, S.M.; De la Cruz, Z.D. Oxidative stress and diabetic retinopathy: Development and treatment. Eye 2017, 31, 1122-1130. [CrossRef]

7. Izzotti, A.; Bagnis, A.; Saccà, S.C. The role of oxidative stress in glaucoma. Mutat. Res. 2006, 612, 105-114. [CrossRef] [PubMed]

8. Donato, L.; Scimone, C.; Alibrandi, S.; Abdalla, E.M.; Nabil, K.M.; D'Angelo, R.; Sidoti, A. New Omics-Derived Perspectives on Retinal Dystrophies: Could Ion Channels-Encoding or Related Genes Act as Modifier of Pathological Phenotype? Int. J. Mol. Sci. 2021, 22, 70. [CrossRef]

9. Donato, L.; Abdalla, E.M.; Scimone, C.; Alibrandi, S.; Rinaldi, C.; Nabil, K.M.; D'Angelo, R.; Sidoti, A. Impairments of Photoreceptor Outer Segments Renewal and Phototransduction Due to a Peripherin Rare Haplotype Variant: Insights from Molecular Modeling. Int. J. Mol. Sci. 2021, 22, 3484. [CrossRef] [PubMed]

10. Scimone, C.; Donato, L.; Alibrandi, S.; Vadalà, M.; Giglia, G.; Sidoti, A.; D'Angelo, R. N-retinylidene-N-retinylethanolamine adduct induces expression of chronic inflammation cytokines in retinal pigment epithelium cells. Exp. Eye Res. 2021, $209,108641$. [CrossRef]

11. Chen, Y.; Mehta, G.; Vasiliou, V. Antioxidant defenses in the ocular surface. Ocul. Surf. 2009, 7, 176-185. [CrossRef]

12. Kaluzhny, Y.; Kinuthia, M.W.; Lapointe, A.M.; Truong, T.; Klausner, M.; Hayden, P. Oxidative stress in corneal injuries of different origin: Utilization of 3D human corneal epithelial tissue model. Exp. Eye Res. 2020, 190, 107867. [CrossRef]

13. Xu, D.; Hu, M.J.; Wang, Y.Q.; Cui, Y.L. Antioxidant Activities of Quercetin and Its Complexes for Medicinal Application. Molecules 2019, 24, 1123. [CrossRef]

14. Song, X.; Wang, Y.; Gao, L. Mechanism of antioxidant properties of quercetin and quercetin-DNA complex. J. Mol. Model. 2020, 26, 133. [CrossRef]

15. Chen, K.T.J.; Anantha, M.; Leung, A.W.Y.; Kulkarni, J.A.; Militao, G.G.C.; Wehbe, M.; Sutherland, B.; Cullis, P.R.; Bally, M.B. Characterization of a liposomal copper(II)-quercetin formulation suitable for parenteral use. Drug Deliv. Transl. Res. 2020, 10, 202-215. [CrossRef] [PubMed]

16. Jain, A.K.; Thanki, K.; Jain, S. Novel self-nanoemulsifying formulation of quercetin: Implications of pro-oxidant activity on the anticancer efficacy. Nanomedicine 2014, 10, 959-969. [CrossRef] [PubMed]

17. Riva, A.; Ronchi, M.; Petrangolini, G.; Bosisio, S.; Allegrini, P. Improved Oral Absorption of Quercetin from Quercetin Phytosome ${ }^{\circledR}$, a New Delivery System Based on Food Grade Lecithin. Eur. J. Drug Metab. Pharm. 2019, 44, 169-177. [CrossRef] 
18. Dian, L.; Yu, E.; Chen, X.; Wen, X.; Zhang, Z.; Qin, L.; Wang, Q.; Li, G.; Wu, C. Enhancing oral bioavailability of quercetin using novel soluplus polymeric micelles. Nanoscale Res. Lett. 2014, 9, 2406. [CrossRef] [PubMed]

19. Morrison, P.W.J.; Khutoryanskiy, V.V. Advances in ophthalmic drug delivery. Ther. Deliv. 2014, 5, 1297-1315. [CrossRef] [PubMed]

20. Mobaraki, M.; Soltani, M.; Zare Harofte, S.; Zoudani, E.L.; Daliri, R.; Aghamirsalim, M.; Raahemifar, K. Biodegradable Nanoparticle for Cornea Drug Delivery: Focus Review. Pharmaceutics 2020, 12, 1232. [CrossRef]

21. Russo, E.; Villa, C. Poloxamer Hydrogels for Biomedical Applications. Pharmaceutics 2019, 11, 671. [CrossRef]

22. Chang, W.-H.; Liu, P.-Y.; Lin, M.-H.; Lu, C.-J.; Chou, H.-Y.; Nian, C.-Y. Applications of Hyaluronic Acid in Ophthalmology and Contact Lenses. Molecules 2021, 26, 671. [CrossRef] [PubMed]

23. Chittasupho, C.; Thongnopkoon, T.; Kewsuwan, P. Surface modification of poly(D,L-lactic-co-glycolic acid) nanoparticles using sodium carboxymethyl cellulose as colloidal stabilize. Curr. Drug Deliv. 2016, 13, 95-104. [CrossRef] [PubMed]

24. Phan, C.-M.; Shukla, M.; Walther, H.; Heynen, M.; Suh, D.; Jones, L. Development of an In Vitro Blink Model for Ophthalmic Drug Delivery. Pharmaceutics 2021, 13, 300. [CrossRef]

25. Chittasupho, C.; Posritong, P.; Ariyawong, P. Stability, Cytotoxicity, and Retinal Pigment Epithelial Cell Binding of Hyaluronic Acid-Coated PLGA Nanoparticles Encapsulating Lutein. AAPS PharmSciTech 2018, 20, 4. [CrossRef]

26. Makadia, H.K.; Siegel, S.J. Poly Lactic-co-Glycolic Acid (PLGA) as Biodegradable Controlled Drug Delivery Carrier. Polymers 2011, 3, 1377-1397. [CrossRef] [PubMed]

27. Khodaverdi, E.; Mirzazadeh Tekie, F.S.; Hadizadeh, F.; Esmaeel, H.; Mohajeri, S.A.; Tabassi, S.A.S.; Zohuri, G. Hydrogels composed of cyclodextrin inclusion complexes with PLGA-PEG-PLGA triblock copolymers as drug delivery systems. AAPS PharmSciTech 2014, 15, 177-188. [CrossRef] [PubMed]

28. Ivanov, I.V.; Mappes, T.; Schaupp, P.; Lappe, C.; Wahl, S. Ultraviolet radiation oxidative stress affects eye health. J. Biophotonics. 2018, 11, e201700377. [CrossRef] [PubMed]

29. Iacopini, P.; Baldi, M.; Storchi, P.; Sebastiani, L. Catechin, epicatechin, quercetin, rutin and resveratrol in red grape: Content, in vitro antioxidant activity and interactions. J. Food Compos. Anal. 2008, 21, 589-598. [CrossRef]

30. Murakami, Y.; Kawata, A.; Ito, S.; Katayama, T.; Fujisawa, S. Radical-scavenging and Anti-inflammatory Activity of Quercetin and Related Compounds and Their Combinations Against RAW264.7 Cells Stimulated with Porphyromonas gingivalis Fimbriae. Relationships between Anti-inflammatory Activity and Quantum Chemical Parameters. Vivo 2015, 29, 701-710.

31. Hines, D.J.; Kaplan, D.L. Poly(lactic-co-glycolic) acid-controlled-release systems: Experimental and modeling insights. Crit. Rev. Ther. Drug Carr. Syst. 2013, 30, 257-276. [CrossRef]

32. Dall'Acqua, S.; Miolo, G.; Innocenti, G.; Caffieri, S. The photodegradation of quercetin: Relation to oxidation. Molecules 2012, 17, 8898-8907. [CrossRef]

33. Wang, J.; Zhao, X.H. Degradation kinetics of fisetin and quercetin in solutions affected by medium $\mathrm{pH}$, temperature and co-existing proteins. J. Serb. Chem. Soc. 2016, 81, 243-253. [CrossRef]

34. Zheng, C.-D.; Li, G.; Li, H.-Q.; Xu, X.-J.; Gao, J.-M.; Zhang, A.-L. DPPH-Scavenging Activities and Structure-Activity Relationships of Phenolic Compounds. Nat. Prod. Commun. 2010, 5. [CrossRef]

35. Abengózar-Vela, A.; Calonge, M.; Stern, M.E.; González-García, M.J.; Enríquez-De-Salamanca, A. Quercetin and Resveratrol Decrease the Inflammatory and Oxidative Responses in Human Ocular Surface Epithelial Cells. Invest. Ophthalmol. Vis. Sci. 2015, 56, 2709-2719. [CrossRef]

36. Purslow, C.; Wolffsohn, J.S. Ocular surface temperature: A review. Eye Contact Lens. 2005, 31, 117-123. [CrossRef]

37. Efron, N.; Young, G.; Brennan, N.A. Ocular surface temperature. Curr. Eye Res. 1989, 8, 901-906.

38. Chittasupho, C.; Manikwar, P.; Krise, J.P.; Siahaan, T.J.; Berkland, C. cIBR effectively targets nanoparticles to LFA-1 on acute lymphoblastic T cells. Mol. Pharm. 2010, 7, 146-155. [CrossRef]

39. Chittasupho, C.; Athikomkulchai, S. Nanoparticles of Combretum quadrangulare leaf extract induce cytotoxicity, apoptosis, cell cycle arrest and anti-migration in lung cancer cells. J. Drug Deliv. Sci. Technol. 2018, 45, 378-387. [CrossRef]

40. Jafari, M.R.; Jones, A.B.; Hikal, A.H.; Williamson, J.S.; Wyandt, C.M. Characterization of drug release from liposomal formulations in ocular fluid. Drug Deliv. 1998, 5, 227-238. [CrossRef] 